Orbis Tertius, vol. XXII, n ${ }^{\circ}$ 25, e045, junio 2017. ISSN 1851-7811

Universidad Nacional de La Plata

Facultad de Humanidades y Ciencias de la Educación

Centro de Estudios de Teoría y Crítica Literaria

\title{
Christine Rivalan Guégo (dir.), Gran Enciclopedia Gallega (1974-1991). La forja de una identidad.
}

Gijón, Trea, 2016, Biblioteconomía y Administración Cultural, 271 páginas.

\author{
Mariela Sánchez
}

Con el aval del Consello da Cultura Galega, la contratapa de este trabajo colectivo sobre la publicación de la Gran Enciclopedia Gallega (de ahora en más, GEG, tal como se abrevia en su estudio) advierte, en franja superior y destacada, la pertenencia a los campos de la "Bilioteconomía” y la “Administración Cultural”. Ya desde esta instancia paratextual es posible presuponer que el interés del volumen va más allá de la dedicación a un colectivo específico, pues lo que se estudia de manera sistemática es un proyecto editorial largamente sostenido en el tiempo, una empresa cultural que da cuenta de una elaboración miscelánea y conjunta. Plan general de la obra, avatares procedimentales y económicos, decisiones metodológicas, mecanismos de distribución y de cobertura de las diferentes entradas de la enciclopedia son solo algunos de los aspectos que, de manera metódica y clara, se presentan y desarrollan. La exposición conlleva, a su vez, observaciones de tipo analítico que, ante todo, suponen la consecución de un objetivo que trasciende la recolección y la organización de datos obtenidos a través de un proceso que contempló tanto el tratamiento de los materiales como la interacción con responsables de la obra.

A comienzos del siglo XXI, un grupo de investigadores sobre prensa, impresos y lectura en el área románica creado en 1981 publica a partir de un seminario un volumen de actas con la contribución de Jean-François Botrel titulada "Enciclopedias, identidad y territorios en el mundo hispánico contemporáneo”. Sobre esa base, se conforma en 2002 un grupo de ocho investigadores de la Universidad de Rennes 2 Haute-Bretagne, pronto reducido a cinco, y se formula el proyecto de plantearse la GEG como objeto de estudio. 
En principio, la investigación se encuentra motivada por el añejo interés por los temas de Galicia en la Universidad de Rennes y por el acercamiento a Les encyclopédies regionales en Espagne, de Philippe Le Ster, leído por el equipo de investigación francés en 1987, también bajo la dirección de Jean-François Botrel.

La publicación en 2016 de este trabajo dirigido por Christine Rivalan Guégo hace viable una mirada distanciada y un acopio de elementos para la reflexión sobre un inicial periodo crítico en lo concerniente a cómo se fue forjando la enciclopedia que es objeto de estudio. Es preciso tener presente que toda la primera etapa de la publicación de la GEG (30 volúmenes, cuando se proyectaban inicialmente 15) se encuentra aún inserta en los últimos años del franquismo, por tanto es especialmente apropiada una consideración que indague en los diversos momentos de realización del proyecto y que favorezca el diálogo con la perspectiva actual de agentes que intervinieron materialmente en la primera formulación.

El libro explora la trayectoria de la GEG y es consecuencia de la investigación llevada a cabo por el aludido equipo de hispanistas constituido por miembros de las Universidades de Rennes 2 Haute-Bretagne y de Angers. Puntualmente, cuenta con las contribuciones personales de Jean François Botrel, Philippe Castellano, Roselyne Mogin-Martin, Moisés Ponce de León Iglesias y Christine Rivalan Guégo, la directora. El prólogo de Ramón Villares patentiza que la inspiración del grupo de hispanistas estuvo a cargo de Botrel. Villares, a su vez, instala una disyuntiva en torno a, por un lado, la contribución de la publicación a la "forja" de una identidad - línea que se encuentra en el subtítulo del volumen y que el historiador parece poner en cuestión — y, por otro lado, la consideración de esta obra como un "lieu de mémoire”, en términos de Nora.

En la investigación sobresale la representatividad de la GEG respecto de las enciclopedias de Cataluña, País Vasco, Valencia, Asturias. Por otra parte, son de subrayar las privilegiadas relaciones entre la Universidad de Rennes 2 - Haute-Bretagne y Galicia, materializadas en trabajos sobre la prensa local en Galicia, la presencia de universitarios de Santiago de Compostela en Rennes, la existencia de un Centro de Estudios Gallegos, con enseñanza de la lengua gallega hasta 2010. Asimismo, Philippe Castellano había sido el autor de un modélico estudio sobre la Enciclopedia Espasa. La publicación preliminar de un artículo a partir de los primeros resultados de la investigación, las reuniones periódicas, primero bajo la dirección de Philippe Castellano y a partir de 2007 bajo la de Christine Rivalan Guégo, y el cuestionario enviado en 2004 a diferentes redactores y colaboradores de la GEG y a Isolina González, secretaria de la editorial, entrevistada en Gijón por Botrel, fueron pasos fundamentales para el volumen Gran Enciclopedia Gallega (1974-1991). La forja de una identidad. Se sucedieron más entrevistas y testimonios (orales y escritos) e informaciones inéditas de otros colaboradores. Desde 2005: el grupo fue multiplicando sus avances, lo que cobra cuerpo en una serie de primeras conclusiones sometidas en marzo de 2008 al parecer de Ramón Villares Paz, Perfecto Conde Muruais y Basilio Losada con motivo del seminario "Le Grande Encyclopédie Galicienne (19741987)”. En este punto, es menester puntualizar que no se trata de un error el año (1987), que difiere del año mencionado como límite final en el libro que reseñamos (1991). La fecha del seminario alude al periodo en que culmina la primera etapa de edición; la del volumen dirigido por Rivalan Guégo abarca, en cambio, el momento en el que se retoma el proyecto.

Las entrevistas iniciales se completaron con la de Xesús Alonso Montero, realizada por la propia Rivalan Guégo en Pontevedra, en agosto de 2008, y también con la presentación de “A imaxe dos galegos no exterior” en el IX Congreso de la Asociación Internacional de Estudos Galegos (AIEG), de julio de 2009, y con una síntesis de las diferentes aportaciones llevada a cabo en el verano de 2011. Todo esto arroja el resultado que ve la luz en el libro colectivo. Son notorias, por tanto, la continuidad y la progresión. La decantación que facilita el manejo de unos tiempos nada forzados ha hecho que se fueran estacionando hipótesis de trabajo y que las diferentes fases de información fueran gradualmente elaboradas en función del avance, con evidentes espacios de intercambio y contrastación. 
Si bien se expone el riesgo de que el lector de hoy pueda encontrar arcaica la representación que se brinda del territorio gallego en la $G E G$, ya que la imagen de Galicia de los últimos tomos es casi tan rural como la de los primeros (y hay 15 años de diferencia), queda claro que en todo momento el trabajo dirigido por Rivalan Guégo está regido por una perspectiva actual, no anclada en la descripción como algo atemporal.

Más allá de la materia gallega y de la pormenorizada presentación estructural, la diversidad de abordaje de las entradas enciclopédicas y la distribución de los encargos para su redacción, la GEG es muestra de un contexto de transformación social y económica desde principios de los 60 que tiene su correlato en los campos cultural, político e intelectual.

El enfoque de este volumen colectivo centrado en la GEG identifica el objetivo de llevar a cabo una acción cultural de gran magnitud — literal y simbólica — como la vía más adecuada para otorgarle a Galicia una visibilidad en cuanto a características, actividades y personalidades que conduzcan a tomar conciencia en un momento clave del siglo XX. Luego de tiempos signados por la persecución, la censura, el exilio y el aniquilamiento de la más amplia gama de libertades, tiempos que oprimieron fuertemente toda expresión de minorías y de alteridades (lingüísticas, culturales, con características geográficas e históricas propias, como es el caso de las autonomías históricas de España: Cataluña, Galicia, el País Vasco) - a menos que se tratara de aspectos pintorescos e inocuos, que eran bien mirados por el franquismo- la GEG procede de la creciente agitación cultural y política que comienza a tener cabida en los 60. Esto, tal como señala Villares en el prólogo, interesará tanto a los grupos del interior como a los grupos del exilio, muy significativos en diferentes puntos de América, como México y Buenos Aires.

El proyecto de la GEG, impulsado por Silverio Cañada sobre la base de la experiencia previa de la Gran Enciclopedia Asturiana tiene sus primeras reuniones en 1971. Se considera que ambas enciclopedias inauguran una serie de publicaciones emblemáticas de los cambios que van interviniendo en la sociedad española al final del franquismo. En ese momento se encuentran el promotor empresarial, Silverio Cañada, y quienes serían los tres coordinadores generales: Xesús Alonso Montero, Francisco Fernández del Riego y Basilio Losada. El programa condensa diversas orientaciones académicas e ideas políticas. Hay tres años de preparación antes de empezar a publicar y se trata de un proyecto editorial absolutamente nuevo en Galicia, para el que hace falta montar, entre otras cosas, una biblioteca (destinada a los redactores) y crear un archivo fotográfico.

Es de destacar cómo se procura dar cuenta a lo largo de todo el volumen dirigido por Rivalan Guégo de la amplitud y la pluralidad del perfil intelectual, profesional y político de las personas convocadas para la puesta en marcha del proyecto de la GEG, así como también del equipo de redacción y colaboradores. Esto se vislumbra no solo en la referencia concreta a los sujetos intervinientes y, ocasionalmente, en la inclusión de sus testimonios, sino también en la selección de los ejemplos, en los que se nota una cuidadosa selección por parte del equipo de hispanistas.

El registro de esta obra, que surgió con el objetivo de ser un compendio de la cultura gallega de fines del siglo XX, se adentra en los tiempos en que fue programada e iniciada (años finales del franquismo), en la publicación (que tiene su mayor desarrollo durante el período de la Transición española y de la configuración, en Galicia, del régimen autonómico) y llega incluso hasta los tiempos recientes en los que la GEG tuvo una suerte de segunda vida mediante una versión ampliada, a cargo del grupo El Progreso, de Lugo, con dirección de Benxamín Casal — sobre la que se explicita una polémica en cuestiones de autorización— así como otra edición posterior, ya sí autorizada.

Se percibe el carácter del objeto de estudio en cuestión en tanto obra de transición, pues hace foco en los cambios en la estructura redaccional y, además, en la elección de temas y la desigual extensión de las principales entradas, que se nota más acotada en los comienzos y más flexible a partir del tercer año de 
publicación. Se tiene en cuenta la marcha de las investigaciones y los avances que se concretan en la aparición de la coherencia del conjunto bajo la heterogeneidad de este tipo de obras. La hipótesis de trabajo más sostenida radica en que la GEG es una empresa de afirmación identitaria. Al surgir a fines del franquismo, es innegable el contexto en el que vuelven a asomar las identidades divergentes del modelo peninsular central. En particular, la identidad gallega, la concerniente a la obra que se estudia, se presenta acertadamente como construcción, como proceso dinámico, no con una concepción esencialista. La pregunta que atraviesa el análisis es en qué medida la GEG abrió un camino para reflexiones posteriores y enciclopédicas sobre la identidad, ya que, como se perfilaba unas líneas más arriba, estas enciclopedias, la gallega, la asturiana, son un producto editorial nuevo en una sociedad en proceso de cambio. Acaso por momentos podría matizarse o problematizarse un tanto el concepto de "identidad", o más aún, el de "identidad profunda", pues difícilmente puede hablarse, en relación con diferentes aspectos, de una identidad gallega, asturiana o catalana. Si bien en todo momento el libro escapa del riesgo de esencialismo y de generalizaciones totalizadoras, cierta insistencia en la identidad puede llegar a dejar un poco de lado las diferencias, incluso en el interior mismo de un colectivo en particular con irrefutables marcas de reconocimiento y de pertenencia. También por momentos puede llegar a inquietar al lector del siglo XXI, especialmente al abocado a estudios gallegos, el uso del término "región” con el que se alude a Galicia en más de una ocasión, ya que, dada la historia atravesada por las autonomías, parece quedar demasiado subrayada una alusión de tipo geográfico-territorial y un tanto relegados por el uso de ese concepto otros elementos. Es cierto que, al ser el territorio y ciertas problemáticas muy específicas vinculadas a él un tema central, es más que atendible la insistencia sobre el tema de la tierra, tanto en la GEG como en el estudio (de hecho, lo territorial en la enciclopedia se encuentra visualmente reforzado y parece ser casi omnipresente); pero por momentos podría matizarse un poco en el análisis su preeminencia como fundamento esencial del ser en Galicia, para descartar cualquier sombra de esencialismo.

Es muy pertinente el señalamiento de imprecisiones que son el reflejo de las dificultades de poner un nombre a unas estructuras administrativas en proceso de cambio, dado el momento de transición que corresponde a la GEG. La investigación francesa alude a los mapas por microzonas, subrayando que no hay mapa de ubicación de Galicia en Europa y que hay uno solo de ubicación de Galicia en España. Al ser tan estrechas las zonas representadas, se avanza la hipótesis de que el procedimiento tal vez responde a una estrategia comercial, a un gesto de atraer a quienes reconocen la zona en todos sus pormenores, y pueden apreciar el rigor y la exactitud de la información facilitada por la GEG, pueden “verse” en la enciclopedia. En esta línea, queda la idea de que la GEG solo está hecha para gallegos; pero lo fundamental es que no ocurre lo mismo, en modo alguno, con la investigación sobre la $G E G$, pues las preguntas, hipótesis y objetivos que guían el trabajo a lo largo de los años trasciende lo local para situarse en un marco editorial de elaboración plural, sucesiva, caleidoscópica: el libro va focalizándose en diferentes entradas y viendo qué trata cada especialista. La concentración en el trabajo colectivo de la enciclopedia (por parte de un equipo, es decir, desde otro encuadre colectivo) permite tanto un registro de los diferentes campos de la GEG como la atención de faltas, ausencias y, entre otras, la marcación de una despareja representación de las mujeres, con excepción quizá de las escritoras. Asimismo, se aborda la permeabilidad de los límites de pertenencia e identificación, como lo que hace que se incluya a autores no nacidos en Galicia pero susceptibles de ser vinculados con ella, como Federico García Lorca.

La elección de los ejemplos que se van intercalando con la exposición descriptivo-analítica constituye un avance contrapuntístico que favorece la exposición. La cadencia narrativa que se logra encauza el trabajo concreto con los volúmenes de la GEG. El tono da buena impresión de lo que fue el trabajo de grupo. El detenimiento en las variadas materias equilibra e integra folklore, lengua, salud, religión, celebraciones, entre muchas otras, desde una respetuosa mirada a distancia. Ese mismo distanciamiento posibilita diversas 
hipótesis sobre criterios de inclusión de materias, lugares, instituciones y nombres propios.

Es destacable la paradoja de que la GEG esté redactada en castellano, lo cual se señala como una “[c]ontradicción aceptada, pero a duras penas asumida, por la mayor parte de los redactores de la GEG”. Y a este respecto también es interesante la referencia a diferentes posicionamientos al respecto entre los principales responsables.

Resulta significativa la apoyatura que brinda al trabajo la incorporación de materiales que formaron parte de la investigación, como la reproducción de una carta de solicitud de colaboradores y un modelo de respuesta, la reproducción de imágenes y la inclusión de diversos anexos que complementan el estudio y exponen la forma en que se fue desarrollando la documentación (cronología de la publicación, entrevistas, cuestionarios, el programa del seminario "La Grande Encyclopédie Galicienne”, de marzo de 2008). Alguno de dichos anexos, además, conlleva una actualización de miradas que ofrecen una reflexión (auto) crítica de actores principales del proyecto.

Estas instancias en alguna medida paratextuales nos conducen a prestar atención una vez más al enriquecedor prólogo de Ramón Villares que, dado su conocimiento del trabajo, funciona como un portal para la publicación, con el plus de una mirada que apuesta en algún caso por disentir o matizar. Se pregunta Villares, por ejemplo, si finalmente la GEG es un "monumento de papel”, denominación que se le atribuye en algún momento en el estudio, y concluye que, desde una perspectiva de compendio de saberes, sí, ya que integró gran parte del caudal enciclopédico del que entonces se disponía; pero desde punto de vista más constructivista (como "monumento conmemorativo"), habría una condición algo más difusa porque carece de la necesaria coherencia y de un respaldo institucional específico.

Para concluir, tanto la visión de conjunto del volumen dirigido por Rivalan Guégo y elaborado, junto con la directora, por Botrel, Castellano, Mogin-Martin y Ponce de León Iglesias, como la concentración en las diferentes zonas que lo componen, dan cuenta de un estudio consecuente y cuidadoso que, lejos de pretender arribar a conclusiones totalizadoras, presenta, ejemplifica y analiza un objeto de estudio complejo, cuya exploración puede echar luz sobre otros emprendimientos atinentes a políticas editoriales que reúnen factores identitarios y culturales en términos amplios, y una suma de materias y saberes específicos múltiples. 